\title{
LUMINOUS PICTURES AS A FORM \\ OF THE CONTEMPORARY VISUAL ART
}

\section{Lidiya Koval ${ }^{1}$}

DOI: https://doi.org/10.30525/978-9934-588-15-0-149

Abstract. The article analyses luminous pictures as a form of contemporary visual art. The emergence of light sources (LEDs) with a fundamentally new way of generating luminous flux has directly influenced not only the theory and practice of functional and decorative lighting, but also visual arts, extending their expressive capabilities. Today, the introduction of LEDs has brought artificial lighting beyond the need of energy saving, creating necessary conditions for widespread use of light not only for utilitarian purposes, but also as a powerful tool of influencing the aesthetics of the environment. Therefore, the analysis of modern forms of using light as an artistic tool will help to reveal the peculiarities of the obtained aesthetic consequences which are the result of increased expressiveness of the image. The aforementioned aspects have actualized the study of luminous pictures as a form of contemporary visual art in order to identify the technological features of their construction and to classify the main visual techniques for creating the pictorial component of such works. Taking into account gaining the most adequate impression of the light environment and light objects is possible in the immediate environment, in the framework of the study the author created a series of works (luminous pictures) in order to exper-imentally outline the peculiarities of visual aesthetics of the result of the application of various artistic techniques in combination with interior lighting. The technology of indoor LED lighting has been used for the production of luminous pictures. This was determined by the following specific features of its use: invisibility of light sources for user's direct visual perception, which promotes the interpretation of illumination as an integral component of the picture image; uniform scattering of light by the surface used for drawing the image. In the course of the study a number of scholarly problems have been solved. The place of luminous pictures in the framework of

\footnotetext{
${ }^{1} \mathrm{PhD}$ in Art History, Associate Professor,

Doctorate in the Department of Architectural Structures,

Kyiv National University of Construction and Architecture, Ukraine

(C) Lidiya Koval
} 
the main classification vectors of contemporary visual arts has been defined. Accordingly, it has been established that luminous pictures belong to the spatial and temporal visual arts, and such visual arts as painting, graphics, collage and various types of reliefs form the basis of luminous pictures. Depending on the spatial form of the embodiment, luminous pictures can be planar or embossed. Besides, the conceptual grounds for the study of light paintings have been defined, namely, the concept of a layer-by-layer perception of light envelopes of various qualities and different light transmittance, which, when using the internal illumination of an image formed with several layers of light-scattering and translucent sheet-plastic, can become the basis for the creation of multilayer luminous objects. The author has elaborated several variants of design of luminous pictures with such technological features as: the case which consists of back and front parts, and the front part, from the aesthetic point of view, performs the function of the passe partout for the picture; LEDs are used as light sources that can be located either around the perimeter or across the entire back panel; the inner surface of the case must be white in order to ensure uniform lighting; the power supply unit is located mainly at the bottom of the structure. As a result, these design proposals are registered as a utility model patent PU 135975. The series of copyrighted works experimentally established, classified and characterized the basic visual techniques of creating a depictive component of different types of luminous pictures, e.g. painting in combination with lighting, black-and-white graphics combined with lighting, multilayered pictures combined with lighting. Further re-searches in this direction should focus on determining the compositional and imaginative features of integrating luminous pictures into interior design, as well as exploring their aesthetic consistency with other components of the interior.

\section{Introduction}

A peculiar illustration of the emotional impact that the combination of light and image can produce to the viewer may be the description of Salvador Dali's childhood impression of his autobiographical work: “...It was a kind of optical theatre, which provided me with the greatest measure of illusion. I have never been able to determine or reconstruct in my mind exactly what it was like... one saw everything as if at the bottom of and through a very limpid and stereoscopic water... The pictures themselves were edged and dotted with colored holes lighted from behind and were transformed 
one into another in an incomprehensible way that could be compared only to the metamorphoses of the so-called 'hypnagogic' images which appear to us in the state of 'half-slumber'" [4, p. 34-35].

If we turn to the question of the importance of exploring the expressive abilities of light and its influence on the development of contemporary art, according to I.O. Kuznetsova [12, p. 143-144]: "the art of Modern and Contemporary periods solves the problems of depicting time and light". Alongside, M.I. Yakovlev, describing a series of experiments related to the visual perception of compositional elements and their consistency, mentions the nature of illumination as the first of the given conditions $[19$, p. 94, 95, 97]. Therefore, the study of modern forms of the use of light as an artistic tool which is used to enhance the expressiveness of the image, will help to identify the peculiarities of the gained aesthetic consequences.

One of the hallmarks of contemporary art is the application of categories of novelty and topicality as criteria for evaluating the importance of works. They are applied in relation to the imagery and topic of the work, as well as to the artistic technique. This fact brings the artists' creative experiments closer to the experimental methods of scientific cognition. Thus, the emergence of light sources (LEDs) with a fundamentally new way of generating luminous flux influences not only the theory and practice of functional and decorative lighting of the environment, but also has direct impact on the visual art, expanding its expressive capabilities.

The aforementioned aspects actualize the study of luminous pictures as a form of contemporary visual art with the aim of identification of the technological features of their construction and classification of the basic visual techniques of creating the pictorial component of such works. To achieve this goal, it is necessary to solve the following research problems: to determine the place of luminous pictures and conceptual bases of their research within the contemporary visual arts, to develop a design of luminous pictures and to create a series of luminous pictures using various visual techniques for the experimental determination of visual result variants.

Today, the introduction of the most energy-efficient LED light sources [18] has brought artificial lighting beyond the limits of energy saving, creating the right conditions for widespread use of light not only in utilitarian purposes but also as a powerful means of influencing the aesthetics of the environment. Therefore, taking into account such advantages of LEDs as miniature sizes, 
safe operating voltage $(12 \mathrm{~V})$ and the purity of the color of radiation, they are used as light sources for the illumination of luminous pictures.

Previously, depending on the technological features of the installation, the author identified such types of LED lighting as "indoor", "exterior" and "hidden" [9, p. 45]. For the production of luminous pictures, the technology of indoor LED illumination is used, due to its following peculiarities: invisibility of light sources for direct visual perception by the user, which promotes the interpretation of illumination as an integral component of the picture; uniform scattering of light by the surface used for drawing the image.

Basing on the fact that obtaining the most adequate impression of the light environment and light objects is possible in the immediate environment, within the study, the author created a number of works (light frames) for the experimental establishment of visual features of the aesthetic result. the use of various fine art techniques in combination with indoor lighting. One part of the luminous pictures (Pics. 1, 5-7), given as examples, was first exhibited in 2016 at the personal exhibition "Touch of Light" and published in the author's catalogue [10], the other (Figure 8-11). is published for the first time.

At the present stage of light design development, its main characteristic is focusing on the qualitative values of lighting. Light design, having combined existing ideas in the fields of psychology of perception and stage lighting, is no longer limited to purely quantitative aspects [6, p. 13-23]. For instance, in the theater, the issues of lighting levels and lighting uniformity are not of great importance, and providing the conditions for the visibility of the stage or any technical equipment is not primary purpose of lighting. Its main purpose is to create illusions and to form different perception of subjects and moods, time of day, changes in the weather, by means of light. Therefore, stage lighting served as an example for determining methods and tools for creating decorative light effects of architectural lighting [17, p. 24]. Accordingly, the basic technological techniques and specific aspects of stage lighting, as described by V.S. Barkov [3], were employed as the basis for the creation of a technique for combining images with lighting within some types of luminous pictures.

\section{The place of luminous pictures in the paradigm of the contemporary visual arts}

The study of luminous pictures as a form of contemporary visual art requires, first of all, determining their place among the main classification 
areas of contemporary visual arts. To denote the entire set of arts, within which luminous pictures should be classified, the cultural concept of "visual arts" has been employed [15, p. 36-38]. Such arts use artistic organization of visual perception as sign material.

Modern variants of the species division of the visual arts complement each other, so the performed analysis is based on several classifications. Its basis was the most popular typology in the field of art, grounded on the spacetime principle. Analyzing the material existence of the art form according to this principle, they distinguish between the spatial arts (construct their images in space, without changing or developing in time), temporal (images are developed in time, not in real space) and spatial and temporal or synthetic (their images have both length and duration, materiality and dynamism) [1, p. 347-350]. Luminous pictures belong to the spatial and temporal arts. This is determined by the material form of luminous pictures embodiment, which determines their perception in space, and by the dynamics of interior illumination, owing to which this perception changes over time. Static illuminated luminous pictures are also spatial and temporal, as they have two states: with inner illumination on they are visually perceived as a light object; with inner illumination off they are perceived as a usual picture.

Having tangible form and created for perception in the real space, all kinds of fine arts are spatial, in particular, painting, graphics, collage and various types of reliefs that make up the pictorial basis of light paintings. Images in the visual arts are created on a plane (the image is produced on a flat surface) or in space (the image has a certain volume or occupies a certain volume) [8, p. 176-179]. Therefore, depending on the spatial form of the embodiment, luminous pictures can be either planar (Figure 5-11) or relief (Figure 1).

The scheme in Figure 2 shows a graphical generalization of a particular place of luminous pictures within the framework of the main classification directions of contemporary visual arts.

\section{Conceptual base of the research}

The idea of light is formed at crossroads of scientific, religious, philosophical and aesthetic vectors of knowledge [14, p. 3]. Taking into account that the religious and mystical beliefs can be considered as the expression of stable stereotypes of human thinking [2, p. 11], the interpretation of the notion of light contained in religious legends and myths can be used as 


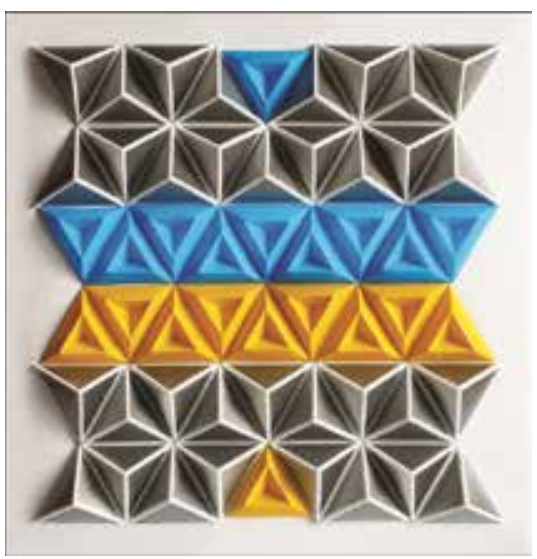

a)

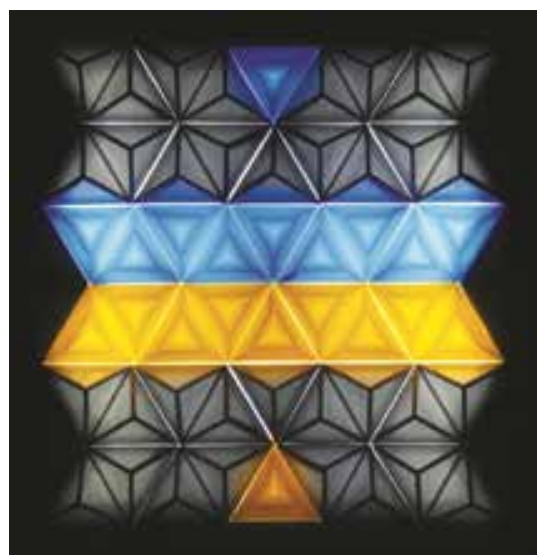

b)

Figure 1. An example of the author's relief luminous picture: a) with inner illumination off; b) with inner illumination on

a basis for creating the concept of luminous picture as an artistic form. For this purpose, "The Zohar" (splendor [2, pp. 148-149]), the most filled with symbolism of the light among othr religious and mystical books, was selected among the texts known from the course of religious studies.

Comments on this book are almost entirely based on explanations of the various levels of cognition of the Creator's light. The universe is described as divided into a number of components of spiritual objects (Partzufim and Sephirot) [13, p. 289] which, by a certain hierarchy, form concentric coats around the Creator. The light emitted by the Creator is a colorless substance, which is impossible to be perceived by a human. Only passing through the Sephirot as through the filters, Creator's light can be perceived by people in a certain color and intensity, which depend on soul level of the subject perceiving this light $[13$, p. 170-171].

The transfer of the above mentioned concept of the spiritual essence of light into the plane of artistic design underlies the concept of layered perception of light shells of different qualities and different light transmittance. It can become the basis for the development of modern understanding of both light space and light objects, being employed similarly to the option of modeling a computer image using independent layers 


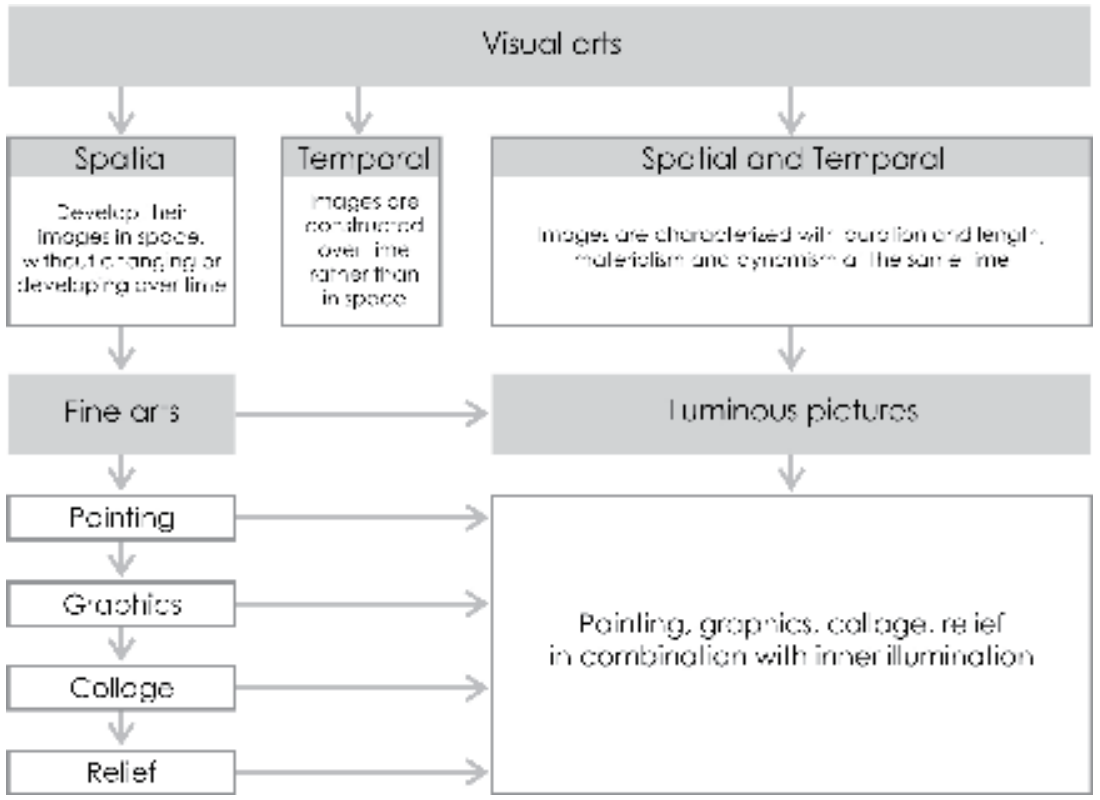

Figure 2. The place of luminous pictures within the framework of the main classification directions of contemporary visual arts

which is inherent in modern graphics editors (Adobe Photoshop, Adobe Illustrator, CorelDRAW). In computer graphics, each of these layers can be adjusted and modified, given a degree of transparency, combined differently with one another. In many ways, this is due to the fact that the computer screen is a light object and the layers of the computer image are virtual. At the material level, the described concept can be embodied in luminous pictures, since the use of inner illumination of an image formed with several layers of sheet plastic of different light transmittance allows to create complex multilayer light objects.

\section{Design and technology solution of luminous pictures}

Grounding on the above mentioned concepts, several design variants of luminous pictures have been elaborated. As a result, these project proposals are registered as a utility model patent PU 135975 [11]. 
Picture 3 demonstrates one of the variants of the luminous picture construction [11, p. 5], that consists of the case (1), which houses the image (2), the light source (3), the control system (4), the power supply (5). The case is made of two parts: the rear (6) and the front (7). The front part (7) consists of a layer of non-translucent material with cutouts (8) and is connected to the rear part (6) with a frame (9). The rear (6) consists of a box (11) and a cover (12) that are bolted together (13). The image (2) is flat, it consists of several parts and is made with application. LEDs located around the perimeter of the back of the case (6) are used as light sources (3). The power supply unit (5) is connected to the standard power supply using a standard connector (10).

Besides, the ratio of the thickness of the luminous picture case to the height and length of its front and rear parts are chosen so that the picture is visually perceived as planar (flat). The front part of the case is made of

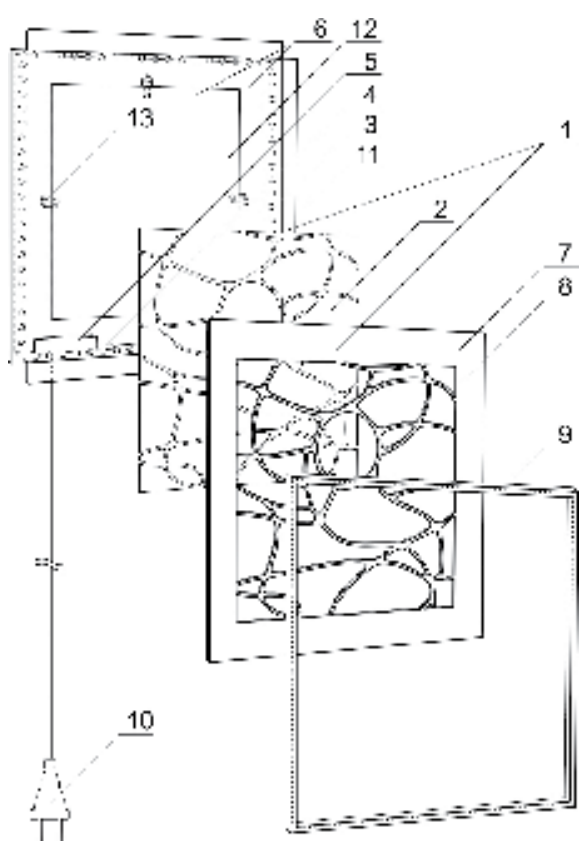

Figure 3. An example of a luminous picture, designed by the author a layer of non-translucent material with a cutout, which, from an aesthetic point of view, performs the function of a passe partout to the image of the picture and can be a component of the entire composition. The utilitarian function of the layer of non-translucent material in the case front is to ensure the uniformity of the illumination of the image by masking luminance difference that can be observed on those areas of the image which are close to near light sources provided that LEDs are placed around the perimeter of the structure. Assembling of the front and rear of the case can be done either with a frame or with glue.

An image of the light picture may consist of separate thin layers of light-scattering or translucent plastic, and its front may be either 
flat or embossed, as well as either single-piece, or parted. The image is created by means of paints, applications from light-scattering and translucent films or plastic, and collage. Luminous pictures are integrated into environment similar to conventional paintings, being hung on the wall, or embedded in the surface of enclosing structures of the room.

The number of light sources for installation should correspond to the artistic design. Color range, statics or dynamics, rhythm and rate of change of inner illumination are determined by the general composition of the picture and are coordinated with the subject matter and mood of the image. LEDs can be positioned either around the perimeter or throughout the case rear. Luminous pictures in Figure 1, 5-11 have perimeter option of LEDs layout. The inner surface of the case must be white for better light diffusion and uniformity of illumination. The power supply unit is preferably located at the bottom of the structure.

Figure 1, 5-11 present the author's rectangular-shaped luminous pictures as examples. However, luminous pictures cases, and, accordingly, the image format, can be of any simple geometric shape. In Picture 4 several variants of luminous pictures of different case shape (1) and the format of the image (2), according to [11, p. 8], are demonstrated. In this case, several luminous pictures can be combined into a single structure circuit (15), with a common connection to the power supply (16).

\section{Painting combined with lighting}

In the early XX century, V.V. Kandinsky, comparing music to painting, specified that music had time as an element of duration, but painting, being deprived of this means, can bring the whole content of a work to the viewer's consciousness at any moment [7, p. 32]. Today, it can be stated that, in addition to the benefits of painting outlined by Kandinsky, this kind of art has obtained time as an expressive means. With the help of a predefined dynamic interior lighting scenario, one can reproduce a number of possible color choices of any static image in one picture. Consequently, modern technological opportunities allow to combine a series of paintings with changes of color relations between elements of a composition within a single work.

The interpretation of light is one of the fundamental problems of the fine arts [14, p. 4]. However, light theory is especially significant in the work of the Impressionists, whose dominant purpose was to reflect changes in the 


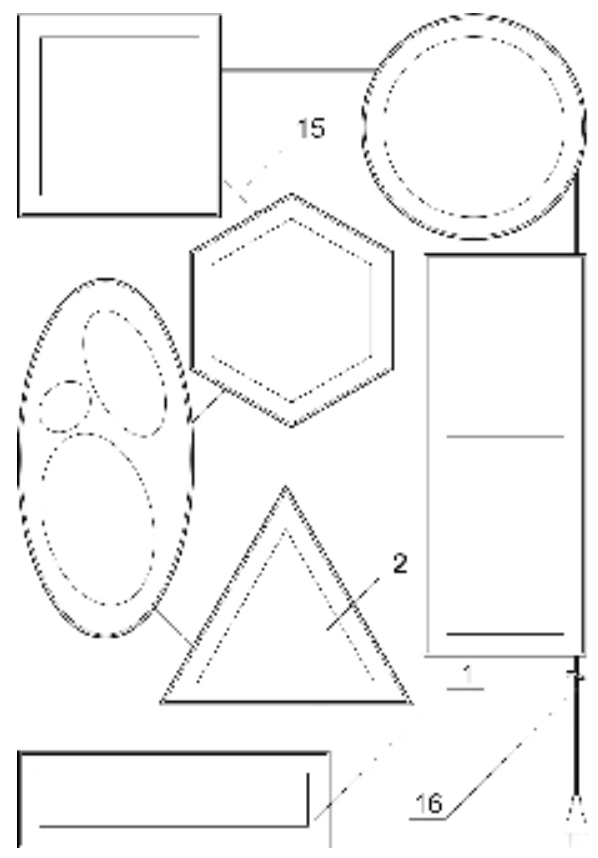

Figure 4. Possible variants of shapes for luminous pictures cases

visual perception of the environment through the inherent dynamics of natural light.

Daylight is constantly changing depending on the state of the atmosphere surrounding the Earth, the seasons, the time of day [3, p. 48]. Claude Monet's fascination with the transmission of the air environment became the basis for the creation of "a new picturesque language and a unique method of working in series [16, p. 131]'. In particular, his series of works, in which the same motif is represented at different times of the day, in different seasons or at different weather include Poplars (1890-1892) [5, p. 16] and Rouen Cathedral (1892-1893). While working on the Poplars series, it took Monet about seven minutes to complete each painting, before the lighting changed. Working on a series of Rouen Cathedral, which included about 30 paintings, the artist made at least 14 sketches a day, trying to capture the nuances of lighting, characteristic of a very short period of time [16, p. 82-90].

At present, the goal that required Monet to create numerous pictures of an object at different times and in different lighting conditions can be achieved in a single work by combining painting with dynamic interior lighting using white and RGB LEDs. As V.V. Kandinsky wrote in one of his theoretical works, "Ultimately, we come to join potentials of different kinds of art [7, p. 32-33]", and a successive development, change and movement of light brings it closer to music [3, p. 5].

When painting with oil paints, artists widely use white pigment in order to obtain different saturation of tints. The ratio of white pigment to the main spectral color characterizes its saturation. Exactly the same results are achieved by 
adding white light to color illumination. By adding red, green and blue (RGB) rays, adjusting the luminous flux from zero to apparent power, one can derive not only all the colors of the spectrum, but also purple shades, such as those obtained by mixing blue and red lighting. The main task of color lighting is to enrich the palette of the artist, so all the main color ratios of light rays must be consistent with the entire design of a particular painting. Light and painting should complement each other [3, p. 46-52].

In case of using white light with color temperature of $3000-5000 \mathrm{~K}$ in combination with RGB for inner illumination of the picture, turning on only white light produces the color ratios of the image elements characteristic of normal daylight. Turning on additional RGB lighting in different proportions of its components (red, green, blue) changes the color of the picture, affecting the color ratios of the image elements, much like changing the color temperature of natural lighting in the morning, evening or night affects the color ratio of real objects.

Picture 5 is an example of the author's luminous picture made with the use of white and RGB inner illumination.

Stained glass paints are most suitable for creating luminous pictures owing to their transparency and broad color palette. Separate colors are quite easy to mix with each other, forming new shades. Applying stainedglass paints on the white scattering surface forms an image that, under normal general lighting, without inner illumination, is perceived as a con-

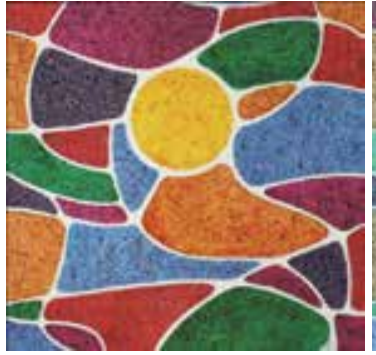

a)

)

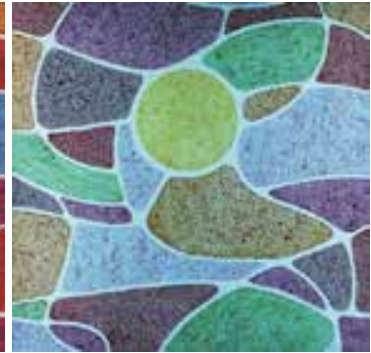

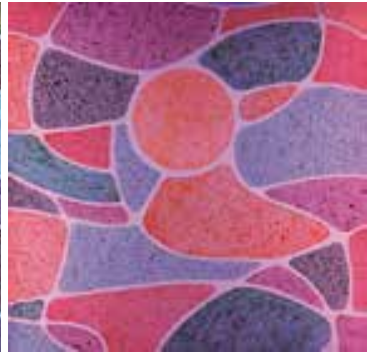

b)

Figure 5. Author's luminous picture "Whole personality" with:

a) white inner illumination; b) white inner illumination with RGB rays in different proportions 
ventional picture. The texture of brushstrokes combines the characteristic properties of the texture of watercolor and oil paints ones: transparency and saturation of watercolor and voluminosity which is inherent in oil paints strokes. However, stained-glass paints strokes have clear boundaries and do not mix smoothly, as in watercolor, and the tonal nuance is achieved not by bleaching, as in oil-painting, but by increasing the level of paint transparency. Therefore, pointillism is the most appropriate when forming images with complex tonal renditions for making voluminous effect, as well as for creating realistic images.

As a technique of painting, pointillism was first used by Seurat. His experiments with split point strokes of contrasting colors resulted into creation of this new pictorial method [16, p. 73]. From 1884, Seurat and Signac began to jointly develop the theory of "divisionalism". Modern scholars use the term "divisionalism" for theory, and "pointillism" for technique" [5, p. 26-27].

A separate direction in the creation of luminous pictures is the combination of conventional painting within the same color range with white and monochromatic lighting. With this approach, the white-lighted picture shows all the available color shades. Due to the gradual dynamics of adding monochromatic illumination to white, these nuances are generalized to a single up-going color, which shows maximum saturation when the white light is finally switched off and only monochromatic (monochrome) is turned on. In Picture 6 examples of author's luminous pictures of this type are demonstrated.

\section{Black-and-white graphics in combination with illumination}

Coating plastic with black, non-translucent paint in combination with interior lighting, you can create silhouette graphic works of high emotional expressiveness. At the same time, the color gamut of lighting and the dynamics of color change is chosen according to the topical and semantic charge of the image in order to enhance its emotional impact on the perceived subject. An example of the author's luminous picture of this type is shown in Figure 7.

A separate technique for such luminous pictures is application of the image on two or more layers of sheet plastic of different light transmittance. In this case, a black and white graphic image, which is visible when the inner illumination is off, is applied to the outer layer of white light-scattering plastic. The inner layer of translucent plastic contains a color image 

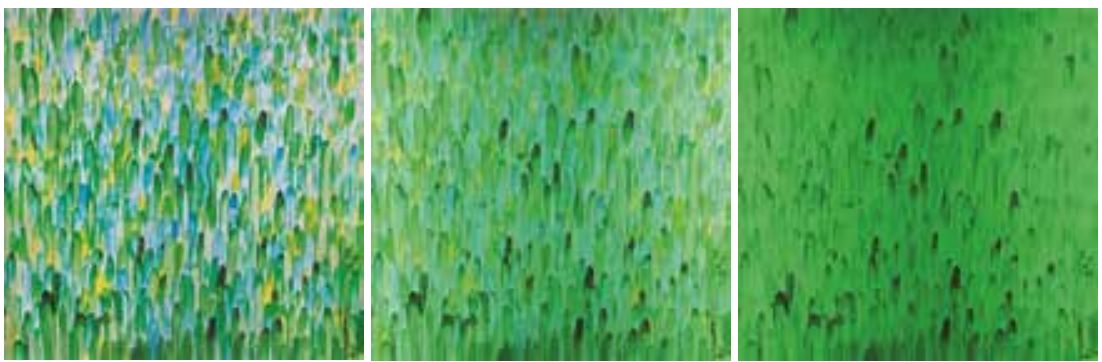

a)
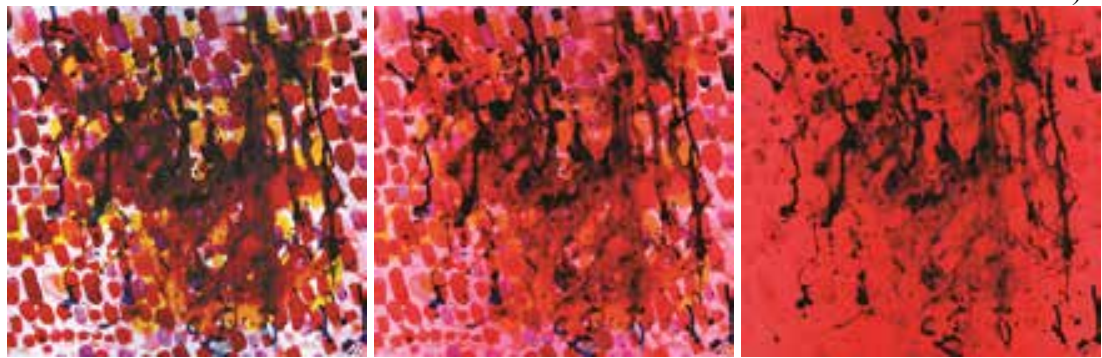

б)

Figure 6. Examples of the author's luminous pictures made with the use of white inner illumination in combination with that of one of the basic colors: a) "Greenness"; b) "Redness"

that becomes visible only when the inner illumination is on. The color of the light can be either white (Figure 8-9) or white in combination with RGB (for a possible change in color). Figure 8-9 is an example of the author's luminous picture with the above described properties.

\section{Multilayered pictures combined with illumination}

Turning to the practice of creating decorative effects in stage lighting $[3$, p. 89,97$]$, it is possible to single out an interesting technique of illumination with the scattered light behind the curtain with a multilayered application of paper or thin fabric, which allows to create soft transitions of shadows and half shadows of different density and transparency. Similar to this technique, the use of applications with many layers of the same or different light transmittance to create an image in luminous pictures, 


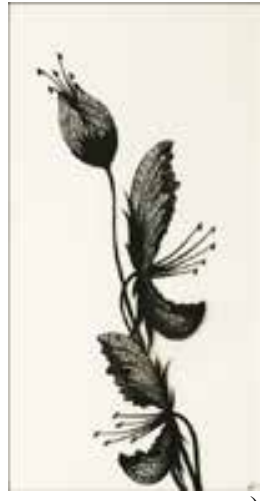

a)

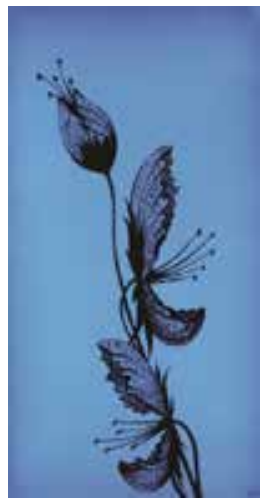

b)

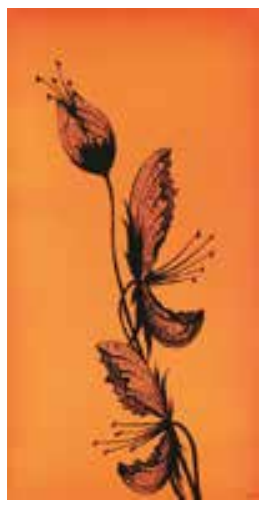

e)

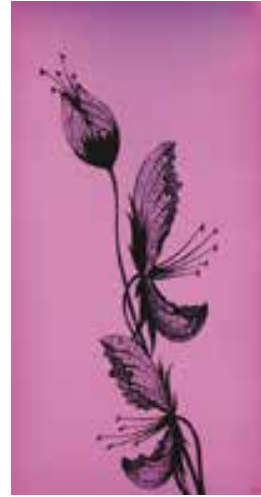

c)

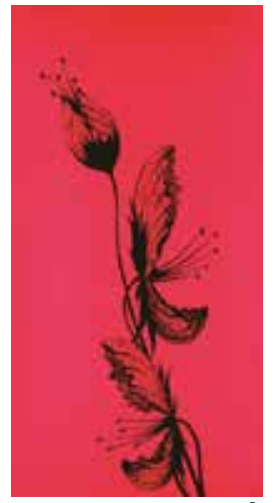

f)

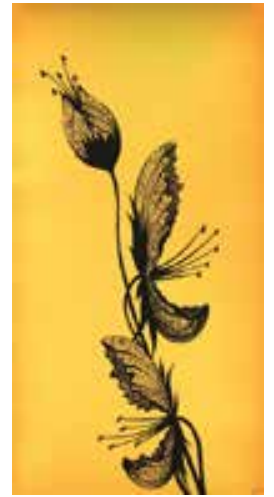

d)

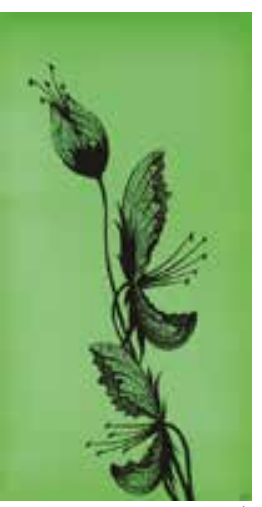

g)

Figure 7. Author's luminous picture "A Flower" with: a) inner illumination off; b-g) several intermediate stages of dynamic inner illumination

provides numerous opportunities for using the best effects of the composition elements. Such luminous pictures may have different variants of embodiment: luminous pictures made with several layers of white light-scattering plastic; luminous pictures composed of several outer layers of white light-diffusing plastic in combination with the inner layers of translucent plastic of other colors, which become visible only when the inner illumination is switched on. 


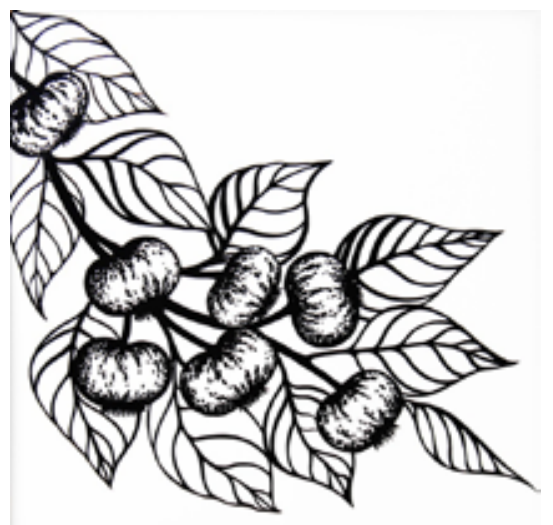

a)

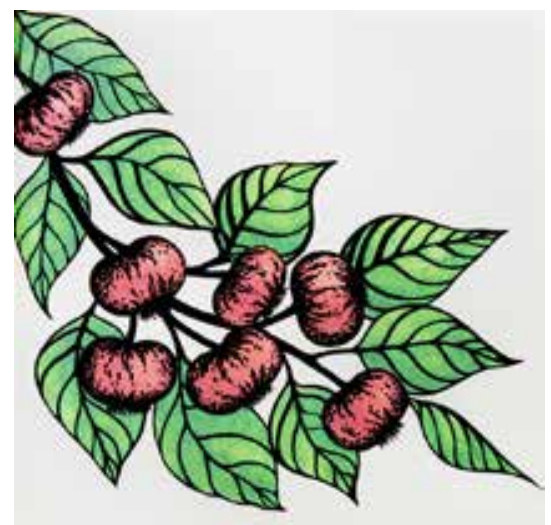

b)

Figure 8. The author's luminous picture "Apples" with: a) inner illumination off; b) inner illumination on

Picture 10 presents variants of the author's luminous pictures, where the image was created by means of applying many layers of white light-scattering plastic $0.3 \mathrm{~mm}$ thick. As seen in Figure 10a, when the inner illumination is off, such an image looks as a white superficial relief. Tonal gradations become articulated only when the inner illumination of the picture is switched on (Figure 10b).

The higher the luminous flux of inner illumination is, the bigger number of tone gradations can be used to create the image. The above examples contain on average about 10 tonal gradations, which are sufficient for graphical processing of both the shape of simple geometric figures and for the tonal nuancing of a portrait (Figure 10c).

Ornamental compositions make a separate direction of luminous pictures of this type. Figure 11 demonstrates an example of the author's luminous picture from the series "Nanoembroidery" which employs an ornamental motif of the Ukrainian cross stitch. Such luminous embroidery can have various embodiments: pictures that look like an embroidery pattern when the illumination is off, and the ornament that imitates embroidery appears when the illumination is on; pictures with visible ornamental on or off; in both variants, the color may change when using white lighting in combination with RGB light. 

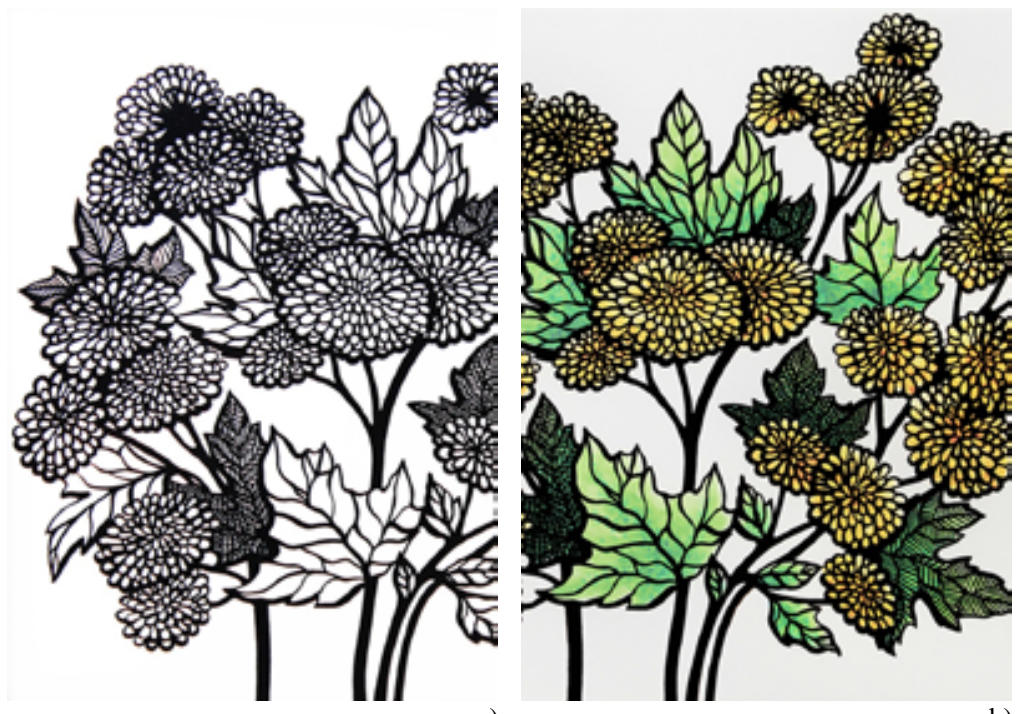

a)

b)

Figure 9. The author's luminous picture "Chrysanthemums" with: a) inner il-lumination off; b) inner illumination on

\section{Conclusions}

Summing up, in the process of studying luminous pictures as a form of contemporary visual art, the following research problems have been solved:

1. The place of luminous pictures within the classification paradigm of modern visual arts has been determined. Accordingly, it is established that luminous pictures belong to the spatial and temporal visual arts, and such visual arts as painting, graphics, collage and various types of reliefs form their figurative basis. Depending on the spatial form of the embodiment, luminous pictures may be planar or embossed.

2. The conceptual bases of luminous pictures studies have been defined, namely the concept of layered perception of light envelopes of different qualities and dif-ferent light transmittance, which when used with inner illumination of the image, formed from several layers of light scattering and light-transparent sheet plastic, can become the basis for creation complex multi-layered light objects.

3. A number of luminous pictures designs has been elaborated. They feature the following: the case consisting of rear and front parts, and the latter, 


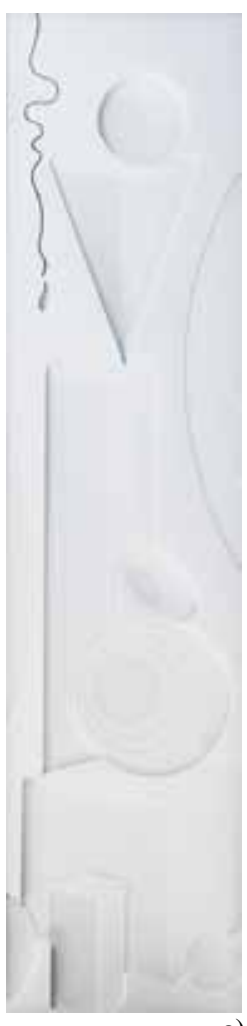

a)

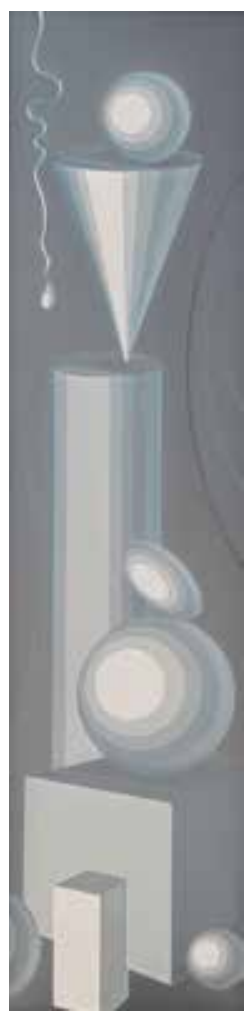

b)

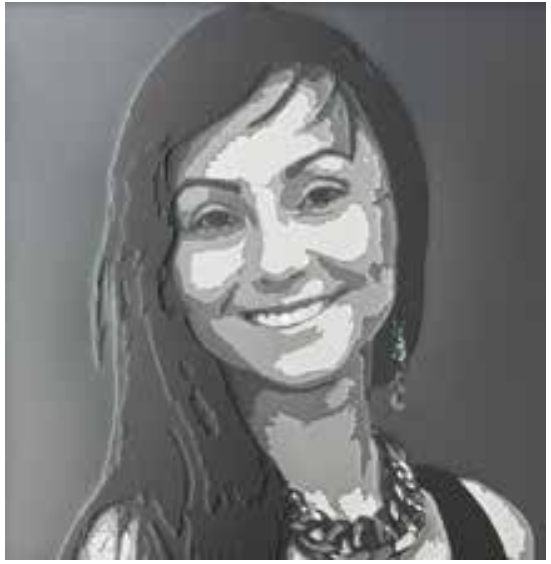

c)

Figure 10. Examples of the author's multilayered luminous pictures created with application technique: a) "Geometric sketch" with inner illumination off; b) "Geometric sketch" with inner illumination on; c) "Self portrait" with inner illumination on

from the aes-thetic point of view, performs the function of the passe partout to the picture; LEDs are used as light sources, which can be located either around the perimeter or throughout the entire rear plane; the inner surface of the case must be white to ensure uniform lighting; the power supply unit is preferably located at the bottom of the structure. As a result, these project proposals are registered in the form of a patent for utility model PU 135975.

4. A series of the author's works has experimentally established, classified and characterized the main visual techniques of creating an image component of different types of luminous pictures, namely: painting in combination with lighting, black and white graphics in combination with lighting, multi-layered paintings combined with lighting. 


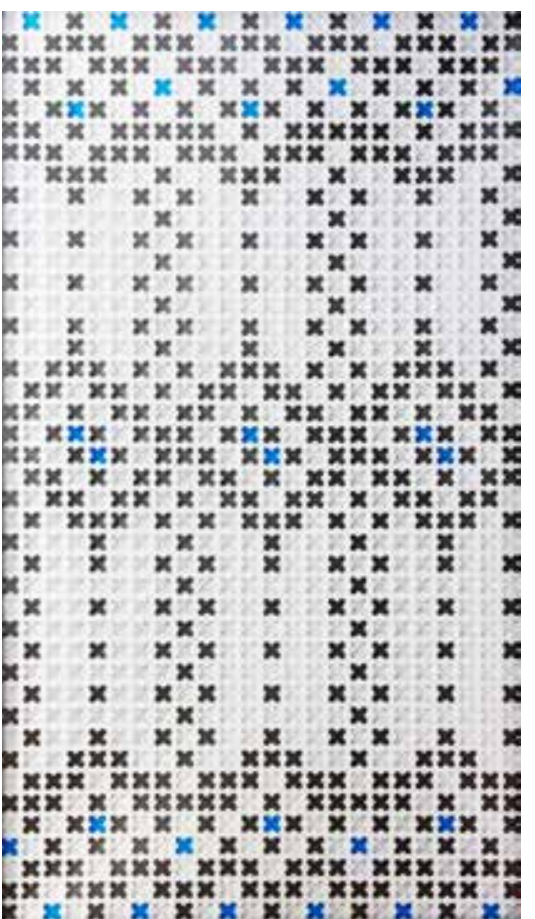

a)

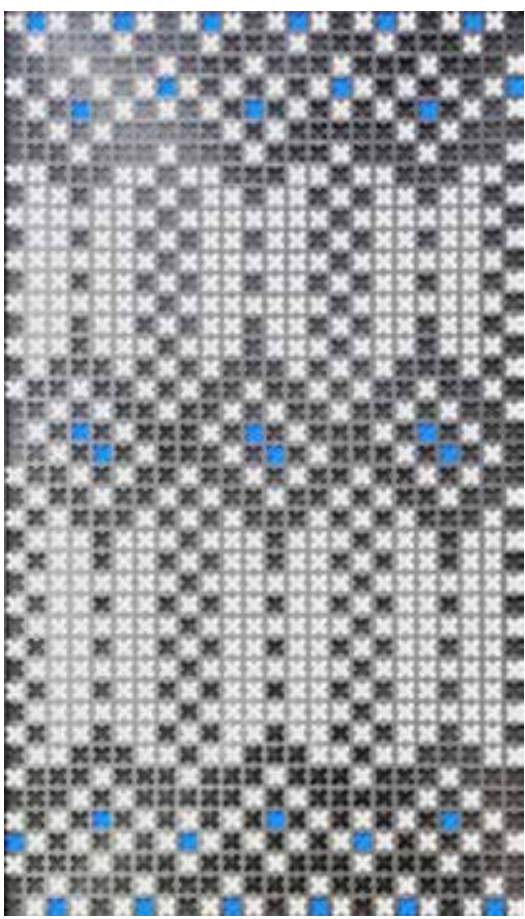

b)

Figure 11. The author's luminous picture "Nanoembroidery № 3" with: a) in-ner illumination off; b) inner illumination on

Further researches in this area should be focused on identifying the compositional and artistic features of integrating luminous pictures into interior design, as well as investigating their aesthetic consistency with other components of the environment.

\section{References:}

1. Arnkheym R. (1974). Iskusstvo i vizual'noe vosprijatie [Art and visual perception]. Moscow: Progress. (in Russian)

2. Barabash O.V., Kachurova S.V., Tytov V.D. (2007). Relighijeznavstvo [Religious Studies]. Kharkiv: FOP Chyzhenko S.Ju. (in Ukrainian)

3. Barkov V.S. (1953). Svetovoe oformlenie spektaklja [Lighting decor of performance]. Moscow: «Iskusstvo». (in Russian) 
4. Dali Sal'vador (1992). Tajnaja zhizn' Sal'vadora Dali, rasskazannaja im samim [The secret life of Salvador Dali, told by himself]. Kishinev: Literaturnyj fond «Axul Z». (in Russian)

5. Dempsi Emi (2008). Stili, shkoly, napravlenija. Putevoditel' po sovremennomu iskusstvu [Styles, schools, directions. Contemporary Art Guide]. Moscow: «Iskusstvo-XXI vek». (in Russian)

6. Julle Oksanen (2017). Design Concepts in Architectural Outdoor Lighting Design Based on Metaphors as a Heuristic Tool. Helsinki: Aalto University School of Arts. Retrieved from: https://shop.aalto.fi/media/filer_public/8b/25/8b253f49-c052-4249b518-5f754dd199b5/oksanen_verkkoversio.pdf (accessed 13 October 2019).

7. Kandinskiy V.V. (2016). O duhovnom v iskusstve [About spiritual in art]. Moscow: Izdatel'stvo «Je». (in Russian)

8. Kapitsa F.S., Koljadich T.M. (2010). Istorija mirovoj kul'tury [History of world culture]. Moscow: AST: SLOVO: Poligrafizdat. (in Russian)

9. Koval L.M. (2014). Dyzajn \& LED-tekhnologhiji [Design \& LED technology]. Zaporizhzhia: ZNTU. (in Ukrainian)

10. Koval L.M. (2016). Katalogh robit 2011-2016 [The catalogue of works 2011-2016]. Zaporizhzhia: Prosvita. (in Ukrainian)

11. Koval L.M. (2018). Patent of Ukraine 125747. Svitlova kartyna [Light picture], zajavl. 11.12.2017, opubl. 25.05.2018, Bjul. № 10. (in Ukrainian)

12. Kuznecova I.O. (2006). Modeljuvannja vizualjnogho spryjnjattja ob'jektiv dyzajnu, dekoratyvno-prykladnogho i obrazotvorchogho mystectva [Modeling of visual perception of objects of design, arts and crafts and fine arts] (Doctoral dissertation). Kyiv: Kyiv National University of Construction and Architecture. (in Ukrainian)

13. Laytman Mikhael' (2003). Serija «Kabbala. Tajnoe uchenie». ZOAR [Series «Kabbalah. Secret doctrine». ZOAR]. Moscow: NPF «Drevo Zhizni», Izdatel'skaja gruppa kabbalah.info. (in Russian)

14. Pavlova E.V. (2012). Kategorija sveta v teorii zritel'nogo vosprijatija ital'janskogo vozrozhdenija: dinamika predstavlenij [The category of light in the theory of visual perception of the Italian Renaissance: the dynamics of ideas] ( $\mathrm{PhD}$ Thesis). Moscow: Research Institute of Theory and History of Fine Arts of the Russian Academy of Arts. (in Russian)

15. Podol'skaya E.A., Ivanova K.A., Lihvar V.D. (2003). Kul'turologija [Cultural science]. Kharkiv: Izd-vo NFaU: Zolotye stranicy. (in Russian)

16. Rapelli P. (2002). Mone [Monet]. Moscow: OOO «Izdatel'stvo AST»: OOO «Izdatel'stvo Astrel'». (in Russian)

17. Rüdiger Ganslandt, Harald Hofmann (1992). Handbook of Lighting Design. Wiesbaden: ERCO Leuchten GmbH, Lüdenscheid Friedr. Vieweg \& Sohn Verlagsgesellschaft mbH, Braunschweig.

18. Sorokin V.M. (2017). Problemy pidvyshhennja energhetychnoji efektyvnosti ta jakosti svitla [Problems of increase of energy efficiency and quality of light]. Svitlodiody: Novynky. Praktyka. Perspektyvy. Materialy konferenciji LED Progress (Kyiv, September 13-15, 2017), pp. 14-15. (in Ukrainian)

19. Yakovljev M.I. (1999). Gheometrychni pryncypy khudozhnjogho formoutvorennja [Geometric principles of artistic shaping] (Doctoral dissertation). Kyiv: Kyiv National University of Construction and Architecture. (in Ukrainian) 